\title{
Influence of Crack on Modal Parameters of Cantilever Beam Using Experimental Modal Analysis
}

\author{
Siva Sankara Babu Chinka ${ }^{1 *}$, Balakrishna Adavi ${ }^{2}$, Srinivasa Rao Putti ${ }^{3}$ \\ ${ }^{1}$ Department of Mechanical Engineering, Lakireddy Balireddy college of Engineering, Mylavaram, India \\ ${ }^{2}$ Department of Mechanical Engineering, SRKR college of Engineering, Bhimavaram, India \\ ${ }^{3}$ Department of Mechanical Engineering, Andhra University College of Engineering-Autonomous, \\ Visakhapatnam, India \\ * Corresponding author email: sivachinka@gmail.com
}

Received: 24 April 2018 / Revised: 21 June 2018 / Accepted: 24 June 2018 / Published: 25 June 2018

\begin{abstract}
In this paper, the dynamic behavior of a cantilever beam without and with crack is observed. An elastic Aluminum cantilever beams having surface crack at various crack positions are considered to analyze dynamically. Crack depth, crack length and crack location are the foremost parameters for describing the health condition of beam in terms of modal parameters such as natural frequency, mode shape and damping ratio. It is crucial to study the influence of crack depth and crack location on modal parameters of the beam for the decent performance and its safety. Crack or damage of structure causes a reduction in stiffness, an intrinsic reduction in resonant frequencies, variation of damping ratios and mode shapes. The broad examination of cantilever beam without crack and with crack has been done using Numerical analysis (Ansys18.0) and experimental modal analysis. To observe the exact higher modes of beam, discretize the beam into small elements. An experimental set up was established for cantilever beam having crack and it was excited by an impact hammer and finally the response was obtained using PCB accelerometer with the help sound and vibration toolkit of NI Lab-view. After obtaining the Frequency response functions (FRFs), the natural frequencies of beam are estimated using peak search method. The effectiveness of experimental modal analysis in terms of natural frequency is validated with numerical analysis results. This paper contains the study of free vibration analysis under the influence of crack at different points along the length of the beam.
\end{abstract}

Keywords: Frequency response functions, Dynamic characteristics, Modal Analysis, Modal parameters, NI LabView

\section{Introduction}

The structures related to the mechanical engineering, civil engineering and aerospace must be free from cracks to ensure safe operation. The health condition of the structure depends on various parameters. The main parameter is damage or crack and that is responsible for the breakdown of the structures. So, it is compulsory to study the influence of crack, based on the natural frequency of the structures in initial stages to identify the health condition. Modal analysis is a process which describes the dynamic behavior of a structure in terms of its modal parameters such as the natural frequency, damping ratio and the mode shape. Loutridis. S [1] established a novel method to detect damages in cantilever beam like structure based on mode decomposition and instantaneous frequency. And the dynamic behavior of a cantilever beam was studied with a breathing crack under harmonic forcing. S.A. Zakeri [2] proposed a numerical approach for an Euler Bernoulli's beam to identify an open edge- crack detection. They have identified the crack depth and crack location by using experimental tests numerical simulations. An analytical approach and experimental approach for crack identification in fixed-free beams using vibration based analysis by Nahvi, $\mathrm{H}$. and Jabbari, M [3]. The cantilever beam is excited by impulse hammer as input and getting the response 
Influence of Crack on Modal Parameters of Cantilever Beam Using Experimental Modal Analysis

by an accelerometer as output in experimentally. From the above methods, estimated normalized frequency and identified the crack in beams based on various normalized crack depths and crack locations.

Khadem, S.E. and Rezaee, M [4] established an investigative method to detecting the crack of rectangular type plates subjected to uniform loads. Owolabi, G.M et al., [5] taken two different beams, one as fixedfree and second one as fixed-fixed beam for damage analysis. Along the length of the beam, they introduced crack at various spans from one end to the other end, with different range of crack depth ratio. They observed the responses, which was taken from the experimental work for all crack locations and analyzed the effect crack dimensions on natural frequency. Nguyen [6] has analyzed rectangular cross section beam and observed mode shapes of a cracked structure using FEM. Also observed the presence of the cracks may be identified depends on mode curves. These shapes have sharp changes or distortions at the crack position if there is a crack. Finally, the crack position estimated, based on sharp changes or shape distortions.

Khiemet al. [7] developed a novel technique for evaluating the resonant frequencies of a multiple cracked beam and based on those frequencies, the number of multiple cracks is evaluated. Gawande. S. H, More. R [8] have studied dynamic behavior of cantilever beam under the influence of crack at various locations along the span of the beam. Gawande SH., More Rudesh R., [9] have established a systematic analytical approach and successfully applied NI LabView software to evaluate the modal parameters. And validate these modal parameters with modal parameters calculated by analytical approach. Xu, Y. F. [10] introduced free response shape (FRS) of beam structure using continuous scanning laser Doppler vibrometer (CSLDV) system. FRS of beam using analytical expressions is compared with FRFs of finite element model. Liu et al. [11] studied reinforced concrete beams for damage identification based on the mode shapes. Castel. A [12] analyzed the cracked reinforced concrete beams for overall stiffness using Finite-element modeling. Chen. $\mathrm{H}$, [13] used the experimental impact testing to estimate the modal parameters of beam like structure, structural health monitoring and damage detection. Colombi P et al. [14] conducted experiments to analyze the fatigue behavior of repaired and cracked steel beams.

Ahmet Can Altunõsüõk et al [15] analyzed the circular cross-sectional steel cantilever beam in Ansys. They have done operational modal analysis of beam to observe the dynamic behavior of multi cracked beam and intact beam. And finally, they validated the Ansys data with analytical and experimental data. H. Ma [16] analyzed the effects of excitation loads such as gravity, magnitude and direction of applied force and crack parameters. Crack parameters like slant crack angles, crack depths and crack locations are also influence the system. Finally, non-linear behavior of the vibrating system investigated by them.

Extensive research was developed by many researchers on damage analysis of the structures to estimate various dynamic behavior parameters. But very few worked on influence of crack on the modal parameters of the beam like structures. In this paper, the influence of crack position and crack depth on modal parameters of cantilever beam was studied based on Frequency response functions (FRFs) and validated with numerical model analysis using Ansys.

\section{Theoretical Vibration Analysis (Modal Analysis)}

In this section analytical model for cantilever beam is considered to determine the first six natural frequencies. The dimensions and properties of the beam are mentioned in table 1.

Table 1: Material properties

\begin{tabular}{|c|c|c|c|c|}
\hline Young's Modulus & Density & Length & Width & Thickness \\
\hline $\mathbf{E}\left(\mathrm{N} / \mathrm{m}^{2}\right)$ & $\boldsymbol{\rho}\left(\mathrm{kg} / \mathrm{m}^{3}\right)$ & $\mathbf{L}(\mathrm{m})$ & $\mathbf{B}(\mathrm{m})$ & $\mathbf{T}(\mathrm{m})$ \\
\hline $6.89 * 10^{10}$ & 2700 & 0.8 & 0.025 & 0.01 \\
\hline
\end{tabular}

The partial differential equation of motion of continuous beam according to Euler-Bernoulli beam theory is

$$
\rho A \frac{\partial^{2} y}{\partial t^{2}}+E I \frac{\partial^{4} Y}{\partial x^{4}}=0
$$




$$
\text { Where } \quad \begin{aligned}
\frac{\partial^{2} y}{\partial t^{2}}+a^{2} \frac{\partial^{4} y}{\partial x^{4}} & =0 \\
a & =\sqrt{\frac{E I}{\rho A}}
\end{aligned}
$$

By applying boundary conditions in the solution of the above partial differential equation for the cantilever beam, then the natural frequency equation is $\cos _{\mathrm{i}} \mathrm{L} \cosh \mathrm{k}_{\mathrm{i}} \mathrm{L}=-1$

Where $\mathrm{k}=(2 n-1) \frac{\pi}{2}$

Where $\mathrm{n}=1,2,3 \ldots \mathrm{n}$

From above equation, $\mathrm{k}_{1}{ }^{2}=3.52 ; \mathrm{k}_{2}{ }^{2}=22 ; \mathrm{k}_{3}{ }^{2}=61.5 ; \mathrm{k}_{4}{ }^{2}=121 ; \mathrm{k}_{5}{ }^{2}=200 ; \mathrm{k}_{6}{ }^{2}=298.55$

$$
\begin{gathered}
\omega_{i}=\frac{k_{i}^{2} a}{L^{2}} \\
\omega_{i}=k_{i}^{2} \sqrt{\frac{E I}{\rho A L^{4}}} \\
\text { Natural frequency }\left(\mathrm{f}_{\mathrm{i}}\right)=\frac{\omega_{i}}{2 \Pi}
\end{gathered}
$$

The first six natural frequencies of the cantilever beam are calculated and represented in table 4 .

\section{Numerical Analysis}

Ansys 18.0 workbench has been used for numerical modal analysis of the cantilever beams with and without cracks. Cantilever beam was drawn and set the material properties as per specification provided in table1. To get the exact dynamic behavior of beam, maintained every $50 \mathrm{~mm}$ crack location from fixed end to free

\begin{tabular}{|c|c|c|c|c|c|c|c|c|c|c|}
\hline \multirow{3}{*}{$\begin{array}{l}\text { Crack } \\
\text { Depth } \\
\text { (in mm) }\end{array}$} & \multirow{3}{*}{$\begin{array}{l}\text { Mode } \\
\text { Numbe } \\
\mathbf{r}\end{array}$} & \multicolumn{9}{|c|}{ Natural Frequency in $\mathrm{Hz}$} \\
\hline & & \multicolumn{9}{|c|}{ Crack location from fixed end in $\mathrm{mm}$} \\
\hline & & 0 & 100 & 200 & 300 & 400 & 500 & 600 & 700 & Undamaged \\
\hline \multirow{6}{*}{2} & 1 & 12.681 & 12.684 & 12.721 & 12.753 & 12.773 & 12.787 & 12.794 & 12.799 & 12.82 \\
\hline & 2 & 79.423 & 79.945 & 80.09 & 79.855 & 79.631 & 79.698 & 79.92 & 80.086 & 80.104 \\
\hline & 3 & 222.16 & 224.1 & 223.2 & 223.28 & 224.06 & 223.03 & 222.65 & 223.7 & 224.07 \\
\hline & 4 & 434.68 & 438.03 & 436.45 & 438.23 & 435.79 & 438.26 & 633.7 & 436.9 & 438.46 \\
\hline & 5 & 717.13 & 721.08 & 722.46 & 718.96 & 722.88 & 719.14 & 722.2 & 718.89 & 723.47 \\
\hline & 6 & 1068.7 & 1072.5 & 1071.3 & 1072.5 & 1070.7 & 1072.5 & 1070.7 & 1069.8 & 1072.6 \\
\hline \multirow{6}{*}{4} & 1 & 12.29 & 12.377 & 12.517 & 12.639 & 12.72 & 12.768 & 12.795 & 12.808 & 12.82 \\
\hline & 2 & 77.821 & 79.488 & 80.057 & 79.07 & 78.23 & 78.35 & 79.386 & 80.051 & 80.104 \\
\hline & 3 & 217.97 & 224.03 & 220.63 & 220.99 & 224.03 & 219.88 & 218.38 & 222.88 & 224.07 \\
\hline & 4 & 427.02 & 436.94 & 430.97 & 437.8 & 428.68 & 437.96 & 429 & 432.51 & 438.46 \\
\hline & 5 & 705.3 & 715.14 & 720.91 & 707.8 & 722.86 & 707.12 & 720.21 & 707.84 & 723.47 \\
\hline & 6 & 1052 & 1058.5 & 1066.6 & 1070.3 & 1054.5 & 1069.7 & 1064.3 & 1050.6 & 1072.6 \\
\hline \multirow{6}{*}{6} & 1 & 11.354 & 11.566 & 11.929 & 12.236 & 12.58 & 12.704 & 12.786 & 12.822 & 12.82 \\
\hline & 2 & 73.751 & 78.393 & 79.956 & 77.00 & 73.918 & 74.334 & 77.033 & 79.904 & 80.104 \\
\hline & 3 & 208.45 & 223.97 & 213.52 & 215.44 & 224.13 & 211.57 & 213.8 & 219.74 & 224.07 \\
\hline & 4 & 411.33 & 434.46 & 417.79 & 437.34 & 409.08 & 437.54 & 408.29 & 417.18 & 438.46 \\
\hline & 5 & 683.04 & 699.37 & 718.21 & 681.42 & 722.92 & 676.66 & 719.02 & 671.16 & 723.47 \\
\hline & 6 & 1022.4 & 1024.1 & 1066.3 & 1069.6 & 1004 & 1068.8 & 1050.9 & 1000.3 & 1072.6 \\
\hline
\end{tabular}
end with $20 \%(2 \mathrm{~mm}), 40 \%(4 \mathrm{~mm})$ and $60 \%(6 \mathrm{~mm})$ of crack depth to total depth ratio of the beam. The natural or resonant frequencies of the above-mentioned beam without and with crack are represented in table 2 for every $100 \mathrm{~mm}$ crack location. The first 6 modes of the cantilever beam are presented in Figure 1. Maintained proper interval of crack location to get exact mode shapes of the beam at higher modes.

Table 2: Natural Frequencies with different crack depths and crack locations of cantilever beam 
Influence of Crack on Modal Parameters of Cantilever Beam Using Experimental Modal Analysis

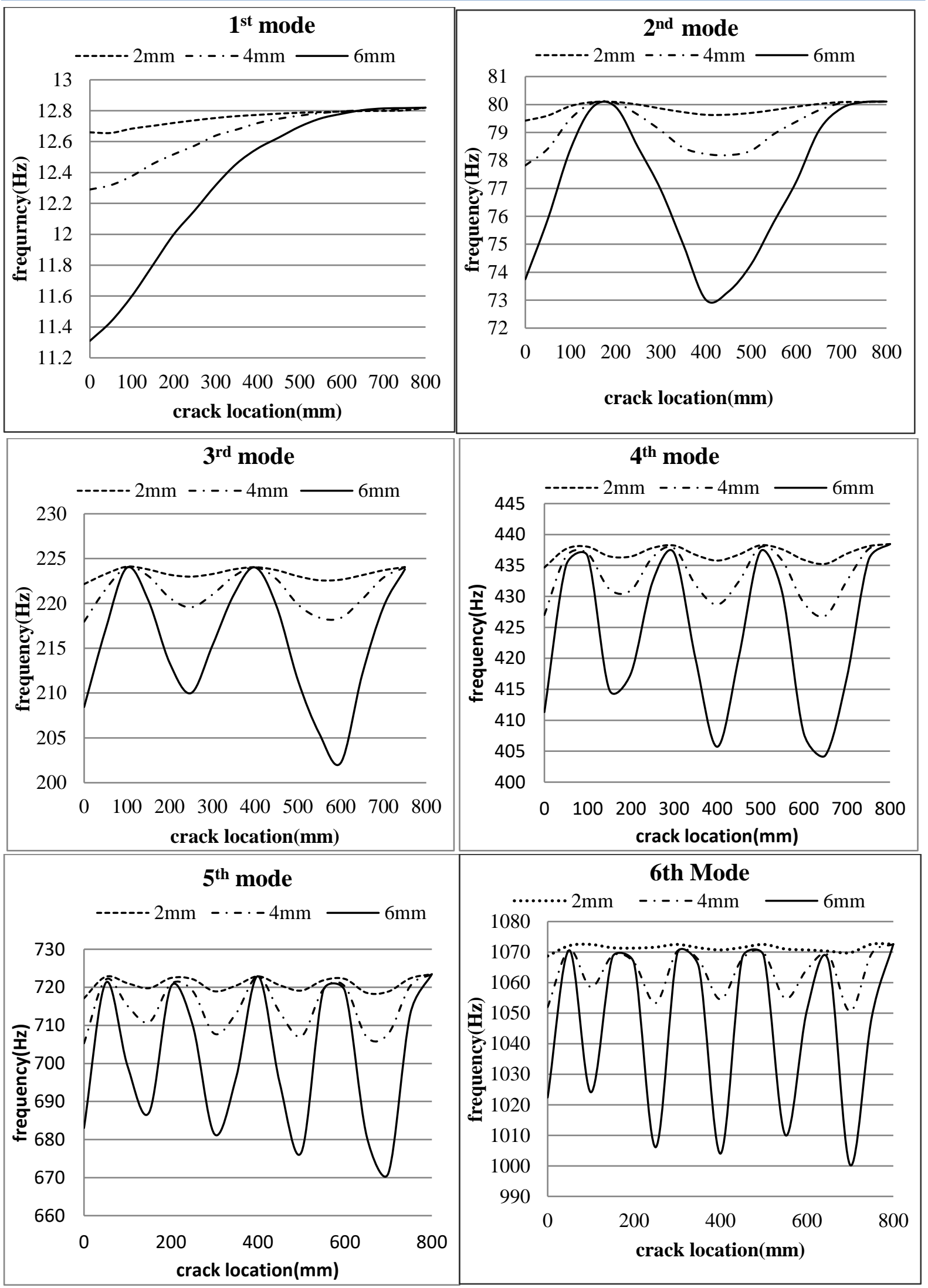

Figure 1: First six modes of the cantilever beam with various crack locations and depths 
Chinka et al., J. Mod. Sim. Mater.; Vol. 1 Issue 1, pp: 16-23, 2018

\section{Experimental Analysis}

To observe the influence of crack on cantilever beam, experimental set-up was developed and is shown in Figure 2. The set-up consists of data acquisition system-DAQ-NI 9234, hi speed USB carrier NI 9162, accelerometer PCB 352C33, impact hammer PCB086C03, NI software with sound and vibration toolbox loaded in computer (PC), specimens, coaxial and $\mathrm{BNC}$ cables.

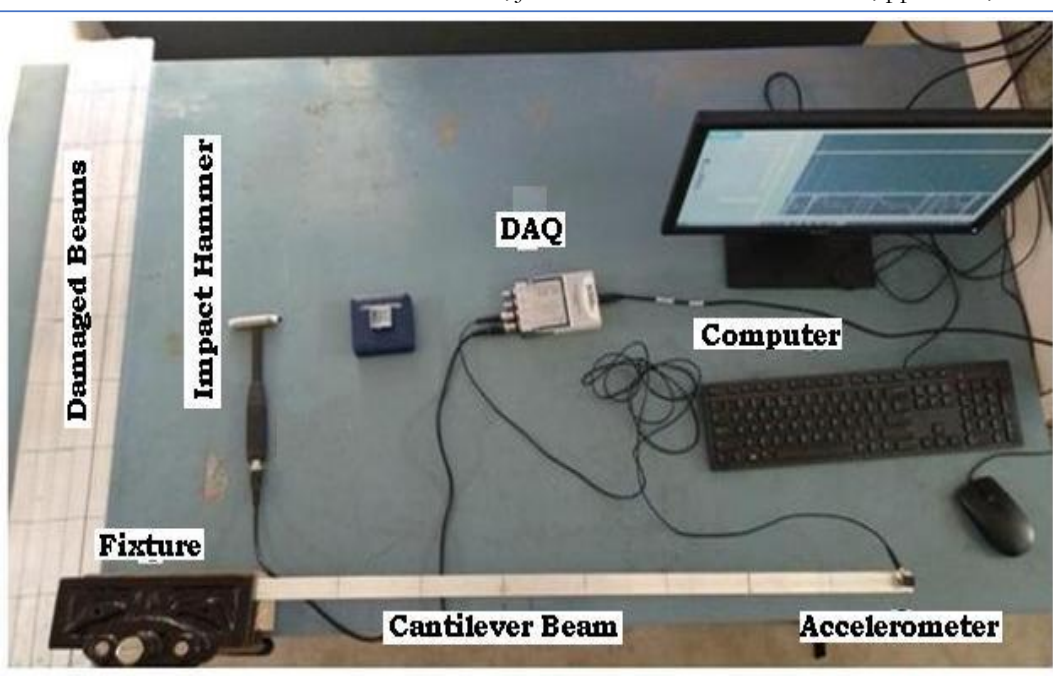

Figure 2: Experimental set-up for modal analysis

The input for free vibration is given by the impact hammer and the output as magnitudes like amplitude, velocity and acceleration in time and frequency domain analysis. Time domain analysis is a record of the response of a dynamic system, as indicated by some measured parameter, as a function of time. In time domain analysis, the time is free variable and response of the system must be logarithmic decrement. Time response analysis is some more difficult to estimate modal parameters compared to Frequency response analysis. In frequency response analysis, the output is the response/impact load that varies with respect to frequency. In this analysis the response parameters are displacement, velocity and acceleration.

Time response functions and frequency response functions of fixed-free beam are obtained by using National instruments LabView software with sound and vibration toolkit by conducting extensive experiment on the beam without and with notch using experimental modal analysis. For observing the first 6 mode shapes of the cantilever beam clearly, maintained a crack for every $100 \mathrm{~mm}$ length. In this work 8 nodes are selected, as per the requirement the number of nodes can be decrease or increase. Each and every node was hit by using impulse hammer which was taken as input and each node gives its corresponding response with respect to time in figure 3 and frequency in figure 4 as output. Natural frequencies of cantilever beam for first 6 modes are observed from the FRFs based on the peak searching method and represented in table 3 .

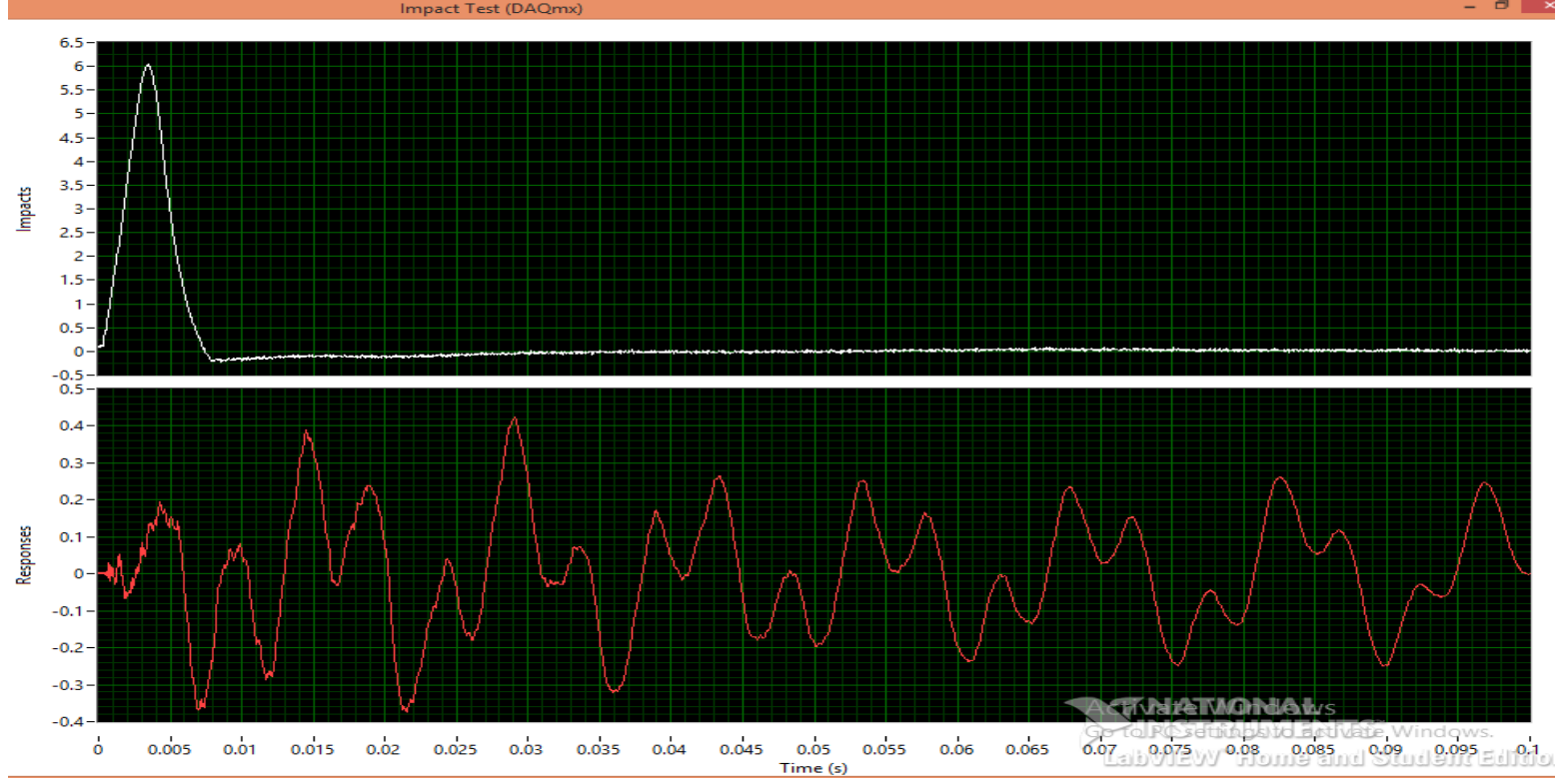

Figure 3: Graph between Impact load and response with respect to time 
Influence of Crack on Modal Parameters of Cantilever Beam Using Experimental Modal Analysis

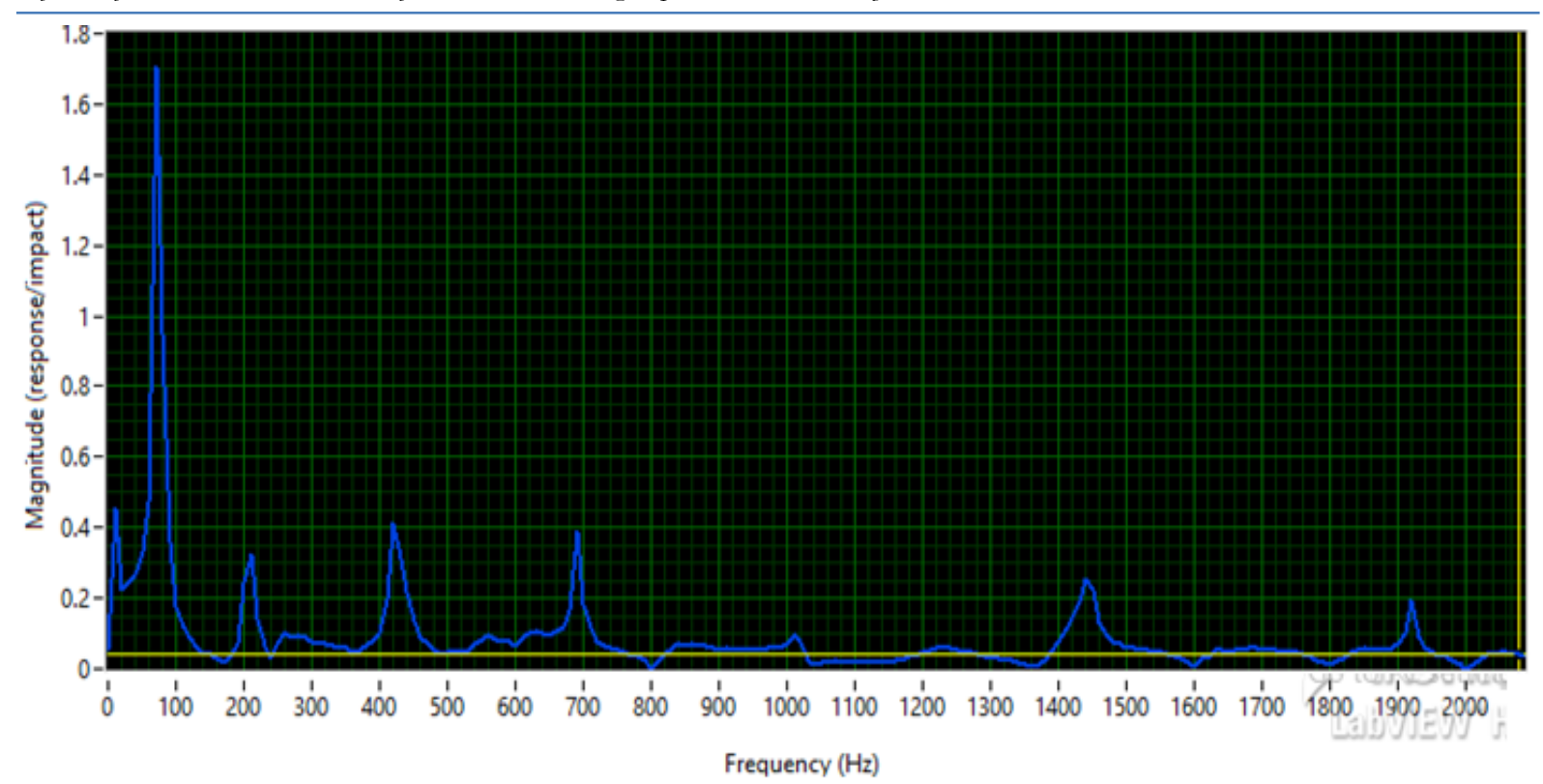

Figure 4: Graph between response/impact with respect to frequency

Table 3: Natural Frequencies of cantilever beam with different crack locations and crack depth ratios

\begin{tabular}{|c|c|c|c|c|c|c|c|c|c|c|}
\hline \multirow{3}{*}{$\begin{array}{l}\text { Crack } \\
\text { Depth } \\
\text { (in } \mathrm{mm} \text { ) }\end{array}$} & \multirow{3}{*}{$\begin{array}{c}\text { Mode } \\
\text { Number }\end{array}$} & \multicolumn{9}{|c|}{ Natural Frequency in $\mathrm{Hz}$} \\
\hline & & \multicolumn{9}{|c|}{ Crack location from fixed end in $\mathrm{mm}$} \\
\hline & & 0 & 100 & 200 & 300 & 400 & 500 & 600 & 700 & Undamaged \\
\hline \multirow{6}{*}{2} & 1 & 11.377 & 12.51 & 11.37 & 11.37 & 11.37 & 11.37 & 11.37 & 11.37 & 11.38 \\
\hline & 2 & 78.32 & 78.59 & 79.02 & 78.15 & 79.45 & 78.29 & 77.9 & 78.10 & 80.13 \\
\hline & 3 & 220.68 & 222.2 & 219.38 & 221.11 & 222.38 & 220.69 & 219 & 220.3 & 199.11 \\
\hline & 4 & 430.2 & 435.7 & 433.08 & 436.19 & 434.8 & 435.7 & 430.2 & 433.2 & 393.53 \\
\hline & 5 & 715.24 & 626.25 & 628.58 & 629.12 & 630.22 & 631.12 & 631.56 & 632.23 & 661.049 \\
\hline & 6 & 1067 & 1069.22 & 1070 & 1070.42 & 1069 & 1068 & 1069.78 & 1067 & 1075.2 \\
\hline \multirow{6}{*}{4} & 1 & 11.37 & \begin{tabular}{|l|}
11.37 \\
\end{tabular} & 11.37 & 11.37 & 11.37 & 11.37 & 11.37 & 11.37 & 11.38 \\
\hline & 2 & 76.54 & 77.54 & 78.18 & 78.54 & 77.54 & 77.9 & 78.54 & 78.94 & 80.13 \\
\hline & 3 & 214.56 & 220.91 & 219.83 & 220.12 & 218.97 & 222.97 & 219.83 & 217.97 & 199.11 \\
\hline & 4 & 425.84 & 432.53 & 427.25 & 436.53 & 427.84 & 435.84 & 429.39 & 430.25 & 393.53 \\
\hline & 5 & 703.94 & \begin{tabular}{|l|}
625.36 \\
\end{tabular} & 627.32 & 627.58 & 628.63 & 629.8 & 630.32 & 631.63 & 661.049 \\
\hline & 6 & 1050.9 & 1055.97 & 1060.63 & 1068.52 & 1053.59 & 1068.52 & 1063.48 & 1049.15 & 1075.2 \\
\hline \multirow{6}{*}{6} & 1 & 11.37 & \begin{tabular}{|l|}
11.37 \\
\end{tabular} & \begin{tabular}{|l|}
11.37 \\
\end{tabular} & 11.37 & 11.37 & 11.37 & 11.37 & 11.37 & 11.38 \\
\hline & 2 & 71.99 & 77.54 & 77.68 & 76.54 & 72.26 & 73.12 & 75.54 & 78.68 & 80.13 \\
\hline & 3 & 206.14 & 220.24 & 212.42 & 213.42 & 221.24 & 209.14 & 211.42 & 217.17 & 199.11 \\
\hline & 4 & 409.74 & 432.91 & 415.09 & 436.25 & 406.19 & 430.39 & 407.29 & 417.15 & 393.53 \\
\hline & 5 & 680.6 & \begin{tabular}{|l|}
619.84 \\
\end{tabular} & 647.7 & 648.19 & 652.91 & 647.15 & 640.04 & 655.19 & 661.049 \\
\hline & 6 & 1020.1 & 1020.25 & 1063.11 & 1059.28 & 1010.56 & 1050.46 & 1063.35 & 1000.7 & 1075.2 \\
\hline
\end{tabular}

\section{$5 \quad$ Results and Discussions}

First six natural frequencies are estimated using theoretical analysis, numerical modal analysis using Ansys and experimental modal analysis tabulated in Table 4 and represented in figure 5.

Table4: First 6 natural frequencies of cantilever beam without damage

\begin{tabular}{|c|c|c|c|c|c|c|}
\hline & \multicolumn{7}{|c|}{ Natural Frequency $(\mathbf{H z})$} \\
\hline & $1^{\text {st }}$ mode & $2^{\text {nd }}$ mode & $3^{\text {rd }}$ mode & $4^{\text {th }}$ mode & $5^{\text {th }}$ mode & $6^{\text {th }}$ mode \\
\hline Theoretical & 12.76 & 79.6 & 223.91 & 438.76 & 725.3 & 1083.47 \\
\hline Ansys & 12.82 & 80.104 & 224.07 & 438.46 & 723.47 & 1072.6 \\
\hline Experiment & 11.38 & 80.13 & 199.11 & 393.53 & 661.049 & 1075.2 \\
\hline
\end{tabular}


Chinka et al., J. Mod. Sim. Mater:; Vol. 1 Issue 1, pp: 16-23, 2018

From Experimental modal analysis, the natural frequencies are exactly identified by peak searching method, which represents there is a change in natural frequency values with respect to crack depth. Crack depth changes form $2 \mathrm{~mm}$ to $6 \mathrm{~mm}$, there is major difference in natural frequency for all crack locations.

For better understanding the effect of crack location and crack depth on natural frequency, the relation between these three parameters are shown in figure 6. The natural frequency changes as crack location changes and it decreases largely if crack depth increases. The natural frequency changes based on the crack locations and various crack depths in case of experimental modal analysis and FEMA, that is represented as samples in figure 6 for $2^{\text {nd }}$ mode and $6^{\text {th }}$ modes.

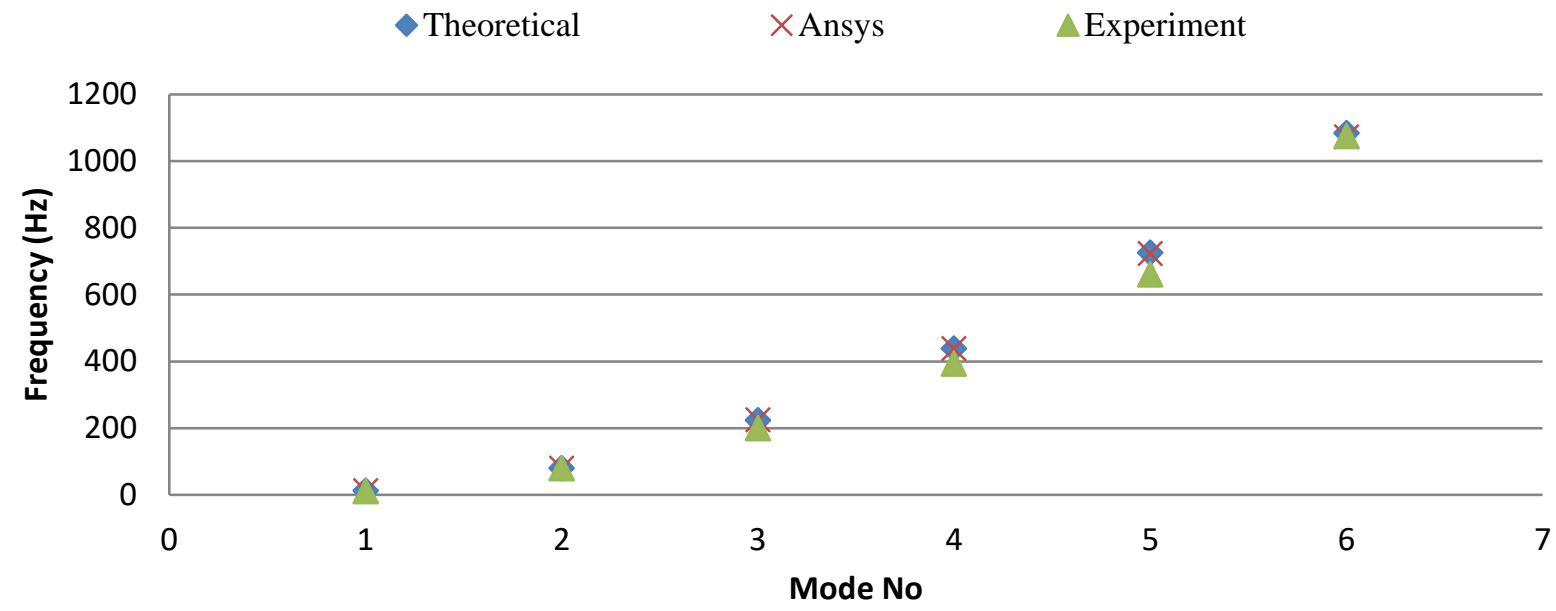

Figure 5: Comparison of natural frequencies of cantilever beam using Ansys, theoretically and experimentally

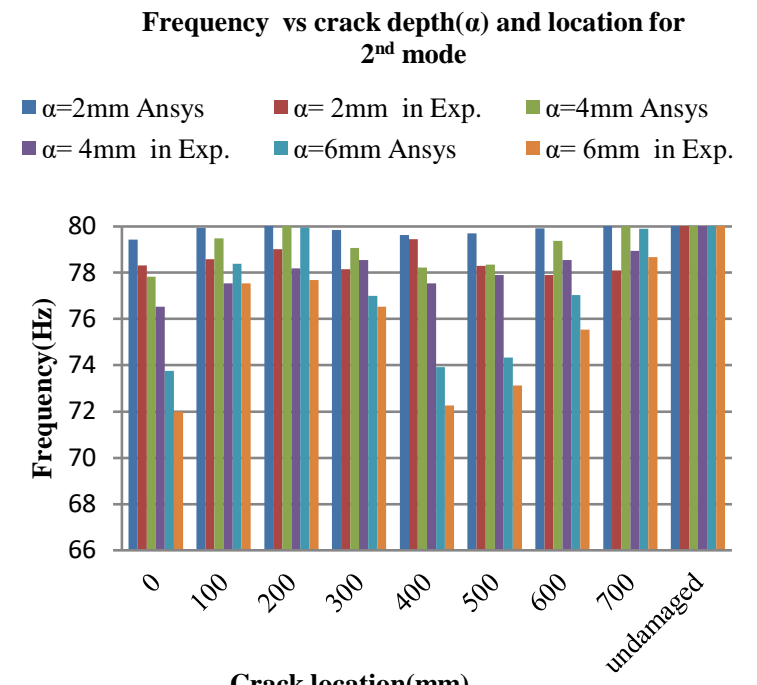

Crack location(mm)

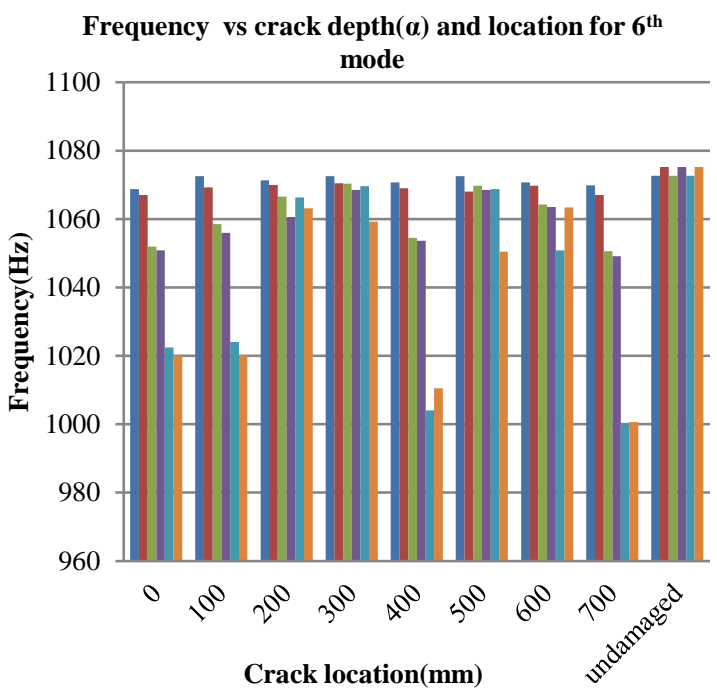

Figure 6: Comparison of numerical and experimental natural frequencies for 2 nd and 6th mode with respect to crack depth $(\alpha)$ and crack location

\section{Conclusions}

Modal analysis is used easily to observe the effect of crack on the natural frequencies and mode shapes for a range of crack locations and crack depth. The frequency response functions (FRFs) obtained from the NI LabView software, modal parameters are estimated using peak search method. The effect of crack dimensions width, depth and position on natural frequency is validated by performing FEMA. It is observed that from experimental and numerical investigations, natural frequency of vibrating structure is within 2$10 \%$ deviation as shown in figure 5 . The following conclusions are observed from this work. Stiffness of the cantilever beam decreases due to the depth of crack increases, and hence decreases in natural frequency. 
In free vibrations, cracked beam frequency is lower than that of the beam without a crack. Crack depth and crack positions are majorly influences the dynamic behaviour of cantilever beam and the natural frequency of beams decreases with increase of transverse crack depth. The natural frequency shift decreases for same depth of crack as the position of the crack changes along the length from fixed end to free end of a cantilever beam.

\section{How to Cite this Article}

S. Chinka, B. Adavi, and S. R. Putti, "Influence of Crack on Modal Parameters of Cantilever Beam Using Experimental Modal Analysis", J. Mod. Sim. Mater., vol. 1, no. 1, pp. 16-23, Jun. 2018. doi:10.21467/jmsm.1.1.16-23

\section{References:}

[1] Loutridis. S. Douka, E. Hadjileontiadisc, L.J. Forced vibration behavior and crack detection of cracked beamsusing instantaneous frequency, Journal of NDT and E international, 38, 411-419, (2005).

[2] Moezi, S.A. Zakeri, E. Zare, A. Nedaei, M. On the application of modified cuckoo optimization algorithm to thecrack detection problem of cantilever Euler-Bernoulli beam, Computers and structures, 157, 42-50, (2015).

[3] Nahvi,H. and Jabbari, M., Crack detection in beams using experimental modal data and finite element model, International Journal of Mechanical Sciences, 47, 1477-1497, (2005).

[4] Khadem, S.E. and Rezaee, M. An analytical approach for obtaining the location and depth of an all-over partthroughnotch on externally in-plane loaded rectangular plate using vibration analysis, Journal of Sound andvibration, 230, 291-308, (2000).

[5] Owolabi, G.M. Swamidas, A.S. J. and Seshadri, R. Crack detection in beams using changes in frequencies andamplitudes of frequency response functions, Journal of sound and vibration, 265,1-22, (2003).

[6] Nguyen, K.V. Mode shapes analysis of a cracked beam and its application for crack detection, Journal ofSound and Vibration, 333, 848-872, (2014).

[7] Khiem, N.T and Toan, L.K. A novel method for crack detection in beam-like structures by measurements ofnatural frequencies, Journal of Sound and Vibration, 333, 4084-4103, (2014).

[8] Gawande. S.H, More.R.R., "Investigations on Effect of Notch on Performance Evaluation of Cantilever Beams" International Journal of Acoustics and Vibration, vol 22, no 4, pp.493-500, 2017.

[9] Gawande Shravan H., More Rudesh R., Effect of Notch Depth \& Location on Modal Natural Frequency of Cantilever Beams, 8, 121 129, (2016).

[10] Xu, Y. F.; Chen, Da-Ming; Zhu, W. D. Damage identification of beam structures using free response shapes obtained by use of a continuously scanning laser Doppler vibrometer system, Mechanical Systems and Signal Processing, Volume 92, p. 226-247(2017),

[11] Liu, S., Zhang, L., Chen, Z., Zhou, J. and Zhu, C. (2016). Mode-specific damage identification methodfor reinforced concrete beams: concept, theory and experiments. Construction and Building Materials, 124, 1090-1099.

[12] Castel, A., Vidal, T. and François, R., Finite-element modeling to calculate the overall stiffness ofcracked reinforced concrete beams. Journal of Structural Engineering, 138, 7, (2012), 889-898.

[13] Chen, H., Kurt, M., Lee, Y.S., McFarland, D.M., Bergman, L.A. and Vakakis, A.F., Experimental system identification of the dynamics of a vibro-impact beam with a view towards structural healthmonitoring and damage detection. Mechanical Systems and Signal Processing, 46, 1, (2014),91-113.

[14] Colombi, P. and Fava, G., Experimental study on the fatigue behavior of cracked steel beamsrepaired with CFRP plates, Engineering Fracture Mechanics, 145, (2015),128-142.

[15] Ahmet Can Altunõsuiõk, Fatih Yesevi Okur, Volkan Kahya, Structural identification of a cantilever beam with multiple cracks: modelling and validation, International Journal of Mechanical Sciences (2017).

[16] H. Ma, J. Zeng, Z. Lang, L. Zhang, Y.Z. Guo, B.C. Wen, Analysis of the dynamic characteristics of a slant-cracked cantilever beam, Mech. Syst. Signal Process, 75 (2016) 261-279.

Publish your research article in AIJR journals-

$\checkmark$ Online Submission and Tracking

$\checkmark$ Peer-Reviewed

$\checkmark$ Rapid decision

$\checkmark$ Immediate Publication after acceptance

$\checkmark \quad$ Articles freely available online

$\checkmark \quad$ Retain full copyright of your article.

Submit your article at journals.aijr.in
Publish your books with AIJR publisher-

$\checkmark$ Publish with ISBN and DOI.

$\checkmark$ Publish Thesis/Dissertation as a Book.

$\checkmark$ Publish Monograph.

$\checkmark$ Publish Edited Volume/ Book.

$\checkmark$ Publish Conference Proceedings

$\checkmark \quad$ Retain full copyright of your books.

Submit your manuscript at books.aijr.org 